\title{
Experimental Analysis of Seismic Performance of Masonry Shear Wall Reinforced with PP-Band Mesh and Plastering Mortar under In-Plane Cyclic Loading
}

\author{
Qiang Zhou (D), Lingyu Yang, and Wenyang Zhao \\ School of Civil Engineering and Architecture, Nanchang University, Nanchang 330031, China \\ Correspondence should be addressed to Qiang Zhou; zhouqiang@ncu.edu.cn
}

Received 30 December 2019; Revised 19 March 2020; Accepted 10 April 2020; Published 28 April 2020

Academic Editor: Jiang Jin; jian0048@e.ntu.edu.sg

Copyright ( 2020 Qiang Zhou et al. This is an open access article distributed under the Creative Commons Attribution License, which permits unrestricted use, distribution, and reproduction in any medium, provided the original work is properly cited.

\begin{abstract}
Masonry structures are widely used in developing countries due to their low cost and simple construction, especially in remote areas, where there are a large number of houses without seismic measures. These buildings are prone to collapse and cause a lot of casualties, even under the action of small earthquakes. For the reinforcement of this structure, a cheap, effective, and easy-toconstruct reinforcement method is urgently needed. Therefore, this article studies the reinforcement method of polypropylene bands (PP-bands). We have carried out low-frequency cyclic loading tests for two PP-band reinforced masonry walls and two compared masonry walls. We mainly studied the influence of PP-band and different compressive strengths of plastering mortar on the masonry wall's seismic capacity. The seismic indicators mainly studied in this article include ultimate bearing capacity, energy dissipation capacity, stiffness degradation, and hysteresis characteristics. The experimental results show that the PP-band can greatly enhance the seismic capacity of the masonry wall. The ultimate bearing capacity, energy dissipation capacity, and displacement ductility of the PP-band reinforced wall are increased by $38 \%-48 \%, 22 \%-47 \%$, and $138 \%-226 \%$.
\end{abstract}

\section{Introduction}

Masonry structure is widely used in developing countries. Due to its heavyweight and brittleness, it is easy to collapse under the action of the earthquake, which causes a large number of casualties and property losses [1]. In the seismic zone around the world, due to the influence of regional conditions and economic imbalances, there are a large number of houses that have not reached the goal of seismic fortification [2]. Facing the current severe seismic prevention and disaster mitigation situation of masonry structures, how to propose an economically effective reinforcement method for masonry structure becomes a key issue [3].

At present, many methods have been proposed for the reinforcement of masonry structures, such as reinforced concrete mortar layer and vertical reinforcement, external posttensioned technique, and external FRP reinforcement methods [4-13]. These methods are applied in many reinforcement projects. Among them, due to the advantages of high strength, corrosion resistance, and easy installation, FRP has become the preferred reinforcement material in the field of seismic reinforcement. However, because the high professional knowledge and expensive cost are required for its reinforcement method, it has some limitations for reinforcing the masonry buildings in economically backward areas.

The PP-band reinforcement method was proposed earlier by Mayorca et al. $[14,15]$. The main idea is to weave the PP-band into a mesh and then lay the PP-band mesh on the wall surface to play the role of reinforcing the wall. Sathiparan et al. [16] discussed the results of a series of diagonal compression tests and out-of-plane tests, which were carried out on nonretrofitted and PP-band retrofitted walls. The experimental results show that, in diagonal compression tests, the retrofitted walls achieved 2.5 times larger strengths and 50 times larger deformations than those of nonretrofitted walls. In out-of-plane tests, the retrofitted walls achieved 7 times larger strengths and 60 times larger 
deformations than the nonretrofitted walls did. Macabuag et al. [17] considered the influence of the direction of the PPband grid on the masonry wall's antishear ability. The experimental results show that vertical bands bear normal compression once sliding of rows occurs, which increases the masonry's frictional resistance to shear sliding; horizontal bands directly bear load by resisting the separation of bricks within the same row. Sathiparn et al. [18] studied the influence of the size of the PP-band mesh on the masonry structure's shear capacity. The experimental results show that residual strength and residual stiffness of the cracked masonry wall, which was reinforced by PP-band, are directly proportional to PP-band density. But when it exceeds the optimum value, improvement ratio of the residual strength and the residual stiffness of the cracked wall does not increase with the amount of the PP-band density. Sathiparn et al. $[19,20]$ carried out a series of simple harmonic shaking table tests for masonry buildings reinforced by PP-band. The experimental results show that the PP-band can effectively maintain the integrity of the wall under large deformation. Moreover, the surface mortar can protect the PP-band mesh from ultraviolet radiation and enhance the bonding between the PP-band and the wall. In 2010, Sun et al. and Zhou et al. $[21,22]$ carried out the shaking table test in a real sense to study the impact of the PP-band reinforcement on masonry structures' seismic capacity. Shaking table tests were carried out on 7 masonry buildings with $1 / 3$ scale reduction. The experimental results show that the PP-band reinforcement can significantly improve the integrity of the wall. When the wall has a large inclination, the wall reinforced by the PPband can be restored to its original position to prevent the wall from collapsing. Saleem et al. [23] carried out the shaking table test by using the method of joint reinforcement of FRP and PP-band. The experimental results show that the joint-reinforced buildings have not collapsed under the action of a severe earthquake. Besides, the shear resistance, energy dissipation, and ductility of the structures have also been significantly improved.

In summary, scholars mainly studied the reinforcement of the PP-band by conducting mechanical property tests on small masonry components and shaking table tests. However, there are not many low-frequency cyclic loading tests on the masonry structure reinforced by the PP-band. In particular, the studies mentioned above have not considered the influence of plastering mortar on the reinforcement of the PP-band. In this paper, the lowfrequency cyclic loading tests are carried out for two PPband reinforced masonry walls and two compared masonry walls. The effects of PP-band reinforcement and different compressive strength of plastering mortar on the seismic performance of masonry walls are studied. The study in this article can provide a reference for the popularization and application of the PP-band reinforcement methods.

\section{Test Overview}

This article mainly conducts a low-frequency cyclic loading test study on two PP-band reinforced walls and two compared walls. The dimension of the four brick walls is $2240 \mathrm{~mm} \times 2000 \mathrm{~mm} \times 240 \mathrm{~mm}$. At the bottom and the top of the brick wall, the concrete beams with a length, width, and height of $3200 \mathrm{~mm} \times 440 \mathrm{~mm} \times 450 \mathrm{~mm}$ and $2240 \mathrm{~mm} \times 240 \mathrm{~mm} \times 300 \mathrm{~mm}$ were cast. The specimens $\mathrm{W}-1$ and $\mathrm{W}-2$ are unreinforced compared specimens, and JW- 1 and JW-2 are the specimens reinforced by the PP-band mesh and plastering mortar.

The block is made of MU10 ordinary sintered clay brick with the dimension of $240 \mathrm{~mm} \times 115 \mathrm{~mm} \times 53 \mathrm{~mm}$. The design strength of the masonry mortars is M2.5. The plastering mortar of the reinforced and unreinforced specimens includes M5 and M10. The design strength of the specimen is composed of three parts: top beam, bottom beam, and brick masonry wall. The reinforced condition of each specimen is shown in Table 1.

\subsection{Mechanical Properties of Materials}

2.1.1. Mechanical Properties of Masonry Materials. To determine the mechanical properties of masonry materials, the compressive strength tests of brick blocks, masonry mortar, and plastering mortar were carried out. According to [24], 10 bricks are randomly chosen from the brick piles, which are used for building the masonry wall. The brick samples were sawed into half. The brick sample is stacked with the opposite side of the cut. The overlap part shall not exceed $100 \mathrm{~mm}$, and the average compressive strength of the brick samples is $11.31 \mathrm{MPa}$. The masonry mortar and plastering mortar test samples are made by the relevant statements in [25]. The size of the mortar cube samples is $70.7 \mathrm{~mm} \times 70.7 \mathrm{~mm} \times 70.7 \mathrm{~mm}$; each set includes three samples; the mortar cube in the same compressive strength is divided into two groups of tests. The compressive strength of the masonry mortar is $2.4 \mathrm{MPa}$. The compressive strength of the plastering mortar of $\mathrm{W}-1$ and $\mathrm{JW}-1$ is $3.8 \mathrm{MPa}$. The compressive strength of the plastering mortar of $\mathrm{W}-2$ and $\mathrm{JW}-2$ is $8.2 \mathrm{MPa}$.

\subsubsection{Mechanical Property Test of Different PP-Band.} According to the relevant statements in [25], we have selected 10 kinds of PP-band with the different size, color, and transparency for tensile test (Figure 1).

The stress-strain curve of each kind of PP-band samples is shown in Figure 2. It can be seen from the figure that the material 9 and material 2 have stronger ultimate tensile strength. But the ultimate tensile strain of material 2 is better, while the elastic modulus of material 9 is larger. Although material 1 has the strongest ultimate tensile strain, its ultimate tensile strength is weak. The ultimate tensile strength of 10 materials is compared and we chose material 1 , material 2, and material 9 as the research object. The basic mechanical properties of material 1 , material 2, and material 9 are shown in Table 2.

It can be seen from the table that the mechanical properties of material 2 are relatively balanced. So material 2 is selected as the reinforcing material for the masonry wall in this test. 
TABLE 1: The reinforced condition of each specimen.

\begin{tabular}{|c|c|c|c|c|c|}
\hline $\begin{array}{l}\text { Specimen } \\
\text { number }\end{array}$ & $\begin{array}{l}\text { Masonry mortar } \\
\text { strength }(\mathrm{MPa})\end{array}$ & $\begin{array}{c}\text { Surface mortar strength } \\
(\mathrm{MPa})\end{array}$ & $\begin{array}{c}\text { Vertical compressive stress } \\
(\mathrm{MPa})\end{array}$ & $\begin{array}{l}\text { PP-band mesh } \\
\text { size }\end{array}$ & Reinforcement form \\
\hline $\mathrm{W}-1$ & 2.5 & 5 & 0.3 & - & Unreinforced \\
\hline $\mathrm{W}-2$ & 2.5 & 10 & 0.3 & - & Unreinforced \\
\hline JW-1 & 2.5 & 5 & 0.3 & $50 \mathrm{~mm} \times 50 \mathrm{~mm}$ & $\begin{array}{l}\text { PP-band mesh } \\
\text { reinforcement }\end{array}$ \\
\hline JW-2 & 2.5 & 10 & 0.3 & $50 \mathrm{~mm} \times 50 \mathrm{~mm}$ & $\begin{array}{l}\text { PP-band mesh } \\
\text { reinforcement }\end{array}$ \\
\hline
\end{tabular}
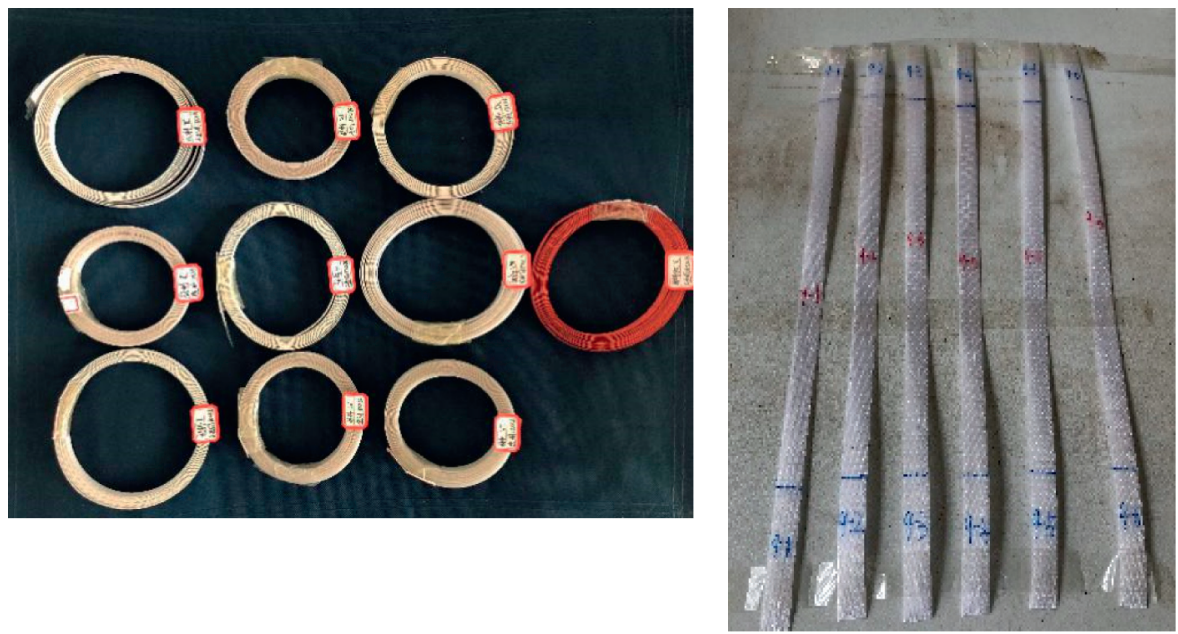

(a)

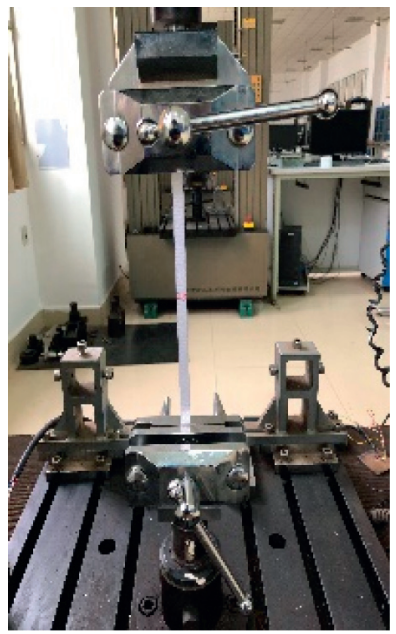

(c) (b)

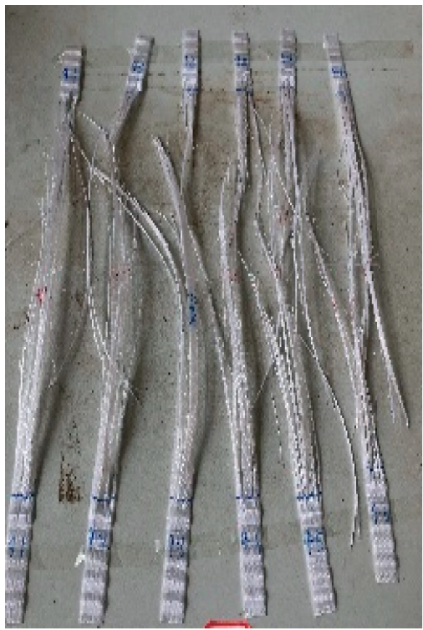

(d)

Figure 1: PP-bands tensile test. (a) 10 kinds of PP-band samples, (b) PP-band before test, (c) tensile mechanical properties test of packing strap, and (d) PP-band after test.

2.2. Reinforcement Scheme. First, the PP-band is woven into a mesh by using an ultrasonic spot welding machine. The grid size in the mesh is $50 \mathrm{~mm} \times 50 \mathrm{~mm}$. Then, the PP-band mesh is laid on the wall surface, and the knots are fastened with packing buckles. The small iron pieces and the iron wires are reserved in the mortar joint for better fixing of the PP-band mesh on the wall surface. Finally, the plastering mortar is plastered on the wall surface. After the specimen is finished, it is artificially watered for 7 days. Then, the specimen is placed at natural temperature until the plastering mortar is sufficiently hardened. The reinforcement process is shown in Figure 3.

2.3. Loading Device and Loading System. The loading device of the test is shown in Figure 4. To simulate the deformation and stress state of the wall under the action of the earthquake, according to [26], the test adopts the load-displacement mixed loading mode. First, the constant vertical force is loaded to the wall and then a cyclic load is applied in 


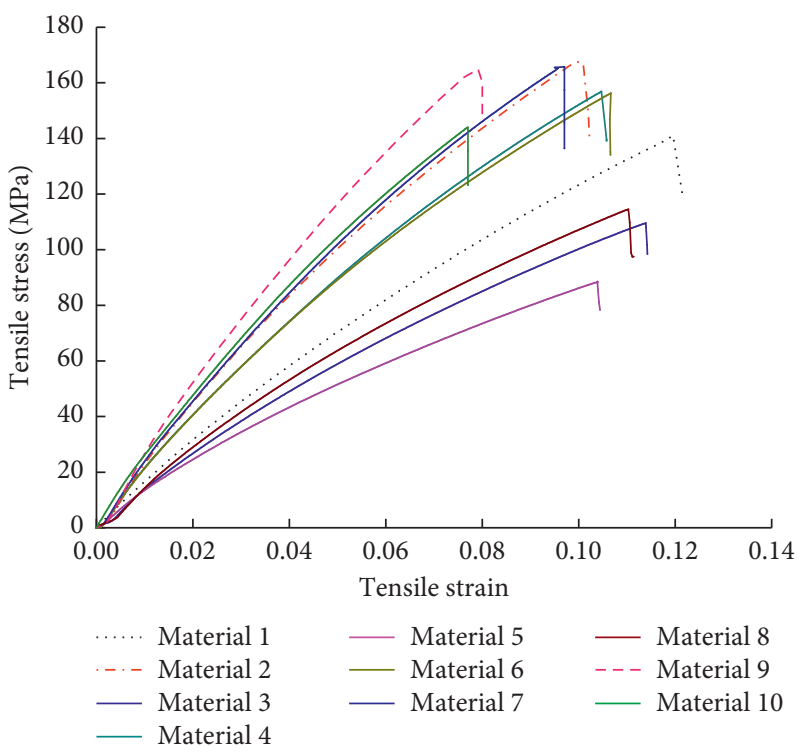

FIGURE 2: Stress-strain curve.

TABLE 2: Mechanical properties of PP-bands.

\begin{tabular}{lccc}
\hline Numbering & Ultimate tensile stress $(\mathrm{MPa})$ & Elastic modulus $(\mathrm{GPa})$ & Ultimate tensile strain $(\mathrm{mm} / \mathrm{mm})$ \\
\hline Material 1 & 143.33 & 1.69 & 0.118 \\
Material 2 & 166.57 & 1.22 & 0.100 \\
Material 9 & 166.22 & 2.11 & 0.078 \\
\hline
\end{tabular}

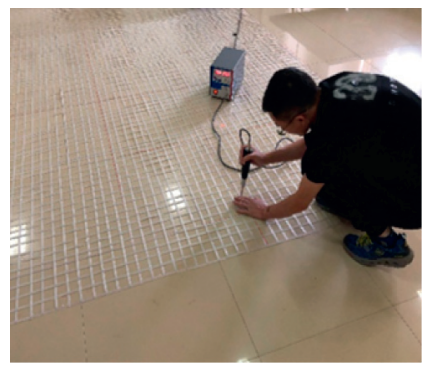

(a)

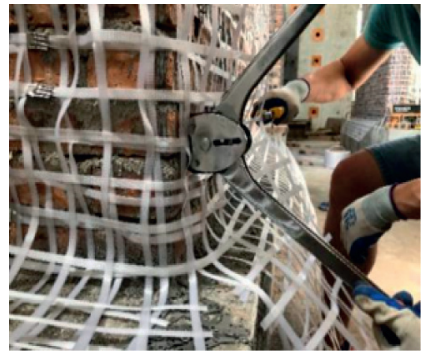

(d)

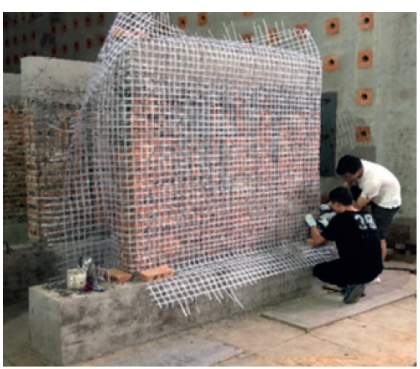

(b)

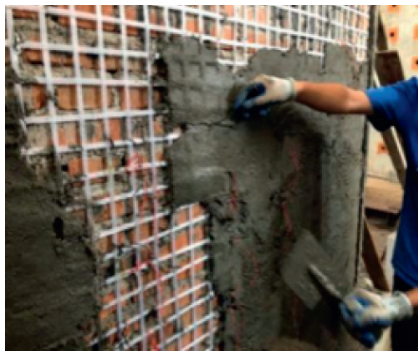

(e)

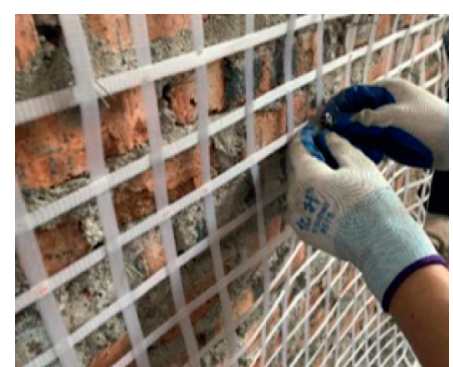

(c)

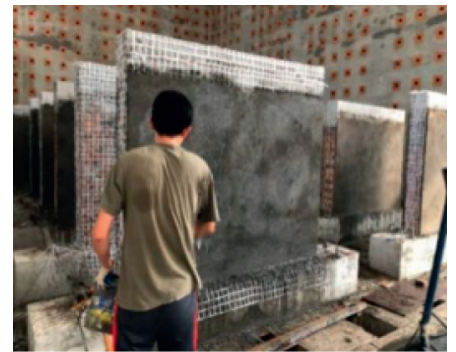

(f)

Figure 3: Strengthening process. (a) Weaving PP-band mesh, (b) laying PP-band, (c) PP-band and wall close, (d) tightening the PP-band, (e) smearing cement mortar, and (f) watering conservation.

the horizontal direction. The horizontal load is applied by using a hydraulic jack with a range of $60 \mathrm{~T}$, which is installed on the reaction wall. The wall is reciprocated in the horizontal direction by using four steel tie bars installed on the top of the wall. The vertical load was uniformly applied to the top beam of the specimen by using two hydraulic jacks with the range of $30 \mathrm{~T}$. The constant vertical force of $144 \mathrm{kN}$ is applied. The stress borne by the top beam was $0.3 \mathrm{MPa}$. During the test, the vertical load remained constant. The vertical load is measured by the load cell at the bottom of the 


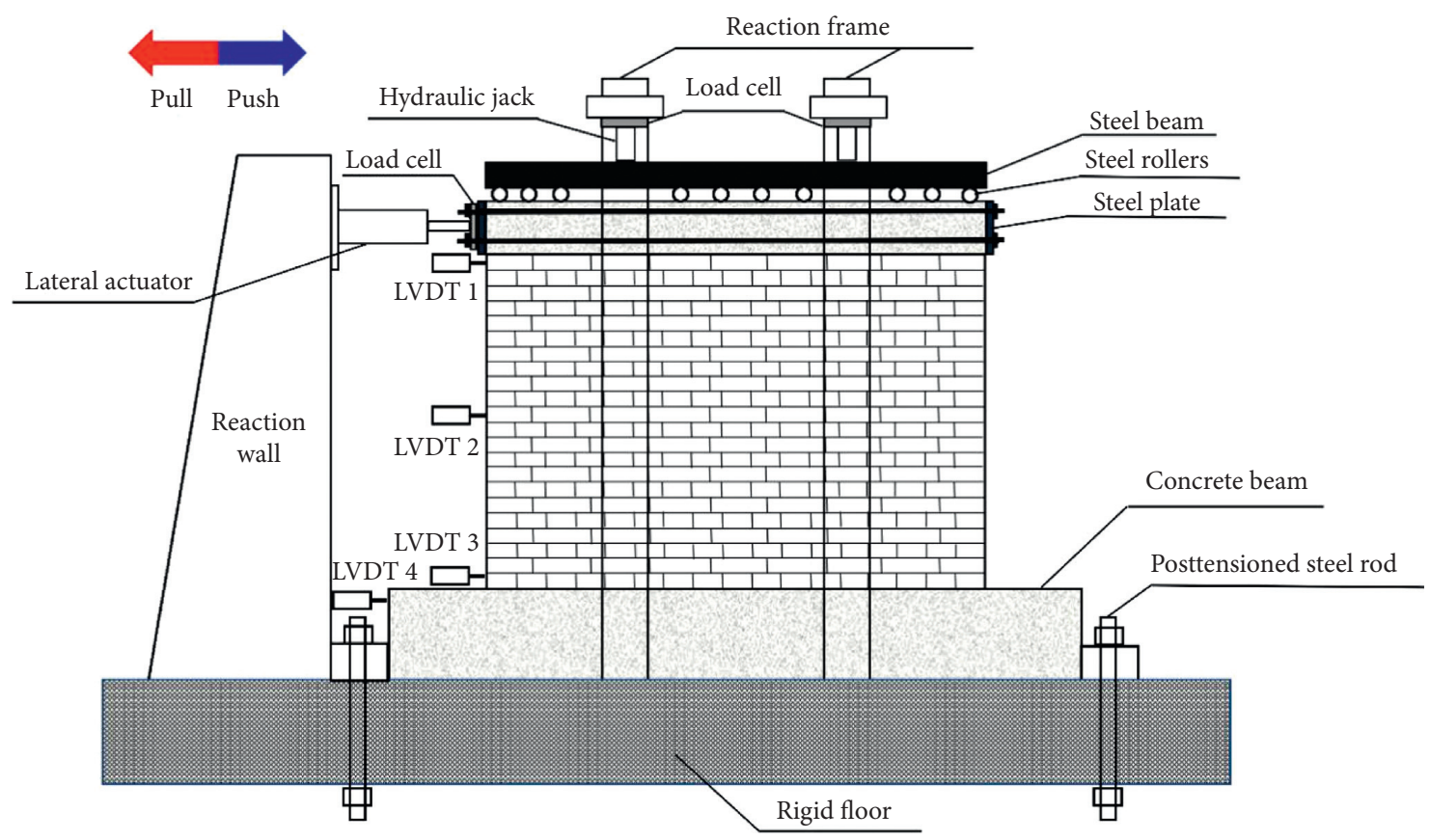

Figure 4: Test setup.

vertical jack. To prevent the wall from sliding during the test, steel beams are installed on both sides of the wall. In this test, four linear variable differential transformers (LVDT) are installed to measure the displacement of the different parts of the wall.

The test adopts the load-displacement mixed loading mode. The loading system diagram is shown in Figure 5. Before the wall is cracked, load control is adopted. The horizontal cyclic force is loaded stage by stage; the increment of each stage is $20 \mathrm{kN}$. Each stage cycle is run for 1 time. After wall cracking, displacement control is adopted. Taking the cracking displacement $\Delta_{c}$ as an increment to load stage by stage, each stage cycle is run for 2 times. Stop loading until the load-bearing capacity of the wall drops to $85 \%$ of the ultimate load.

\section{Test Results and Analysis}

\subsection{Unreinforced Specimen Failure Process}

3.1.1. General Observation for Specimen W-1. Before loading to $110 \mathrm{kN}$, the wall had no visible cracks, and the specimen was basically in the elastic state. When the forward force (from left to right, the same below) loaded to $115 \mathrm{kN}$, the first horizontal crack appeared at the 3rd and 4th bricks layers on the lower left side. The length of this crack was about $65 \mathrm{~cm}$ and the width was about $0.5 \mathrm{~mm}$. When the forward displacement loaded to $1.8 \mathrm{~mm}$, the crack between the $3 \mathrm{rd}$ and 4th brick layers on the left side of the wall developed in the horizontal direction. When the backward displacement (from right to left, the same below) loaded to $1.8 \mathrm{~mm}$, the cracks in the bottom right side of the wall also extended horizontally and formed a through-slit. Due to the formation of horizontal through-slit, no new cracks appeared in the upper part of the wall. As the displacement increased, the wall below the through-slit was squeezed. Finally, a lot of oblique cracks were formed at the lower left and right sides of the horizontal crack. The bricks on both sides of the bottom were crushed and the plastering mortar had a slight shedding. The damage is shown in Figure 6.

3.1.2. General Observation for Specimen W-2. When the reverse force loaded to $120 \mathrm{kN}$, a thin crack with a length of about $20 \mathrm{~cm}$ and a width of about $0.2 \mathrm{~mm}$ appeared at the lower right side of the wall. When the forward displacement loaded to $1 \mathrm{~mm}$, a horizontal crack with a length of about $80 \mathrm{~cm}$ and a crack width of about $1 \mathrm{~mm}$ appeared at the lower left side of the wall. When the displacement loaded to $1.5 \mathrm{~mm}$, the cracks on both sides continued to develop in the middle horizontal direction. When the displacement loaded to $2 \mathrm{~mm}$, the horizontal cracks between the 7 th and 8 th brick layers on the left and right sides were connected. When loaded to $3 \mathrm{~mm}$, the horizontal cracks on both sides of the wall penetrated down to the bottom of the wall along the diagonal of about $45^{\circ}$. After that, as the displacement increased, the crack width gradually increased, part of the plastering mortar fell off, and a vertical crack was formed at the bottom left side of the wall. The damage is shown in Figure 7.

\subsection{PP-Band Reinforcement Specimen Destruction Process}

3.2.1. General Observation for Specimen JW-1. There was no obvious damage in the early stage of loading. When loaded to $115 \mathrm{kN}$, there was a fine crack of about $15 \mathrm{~cm}$ in length and about $0.2 \mathrm{~mm}$ in width appeared at the top of the wall. With the increase of load, the crack did not extend along this crack. When loaded to $130 \mathrm{kN}$, a horizontal crack with a 


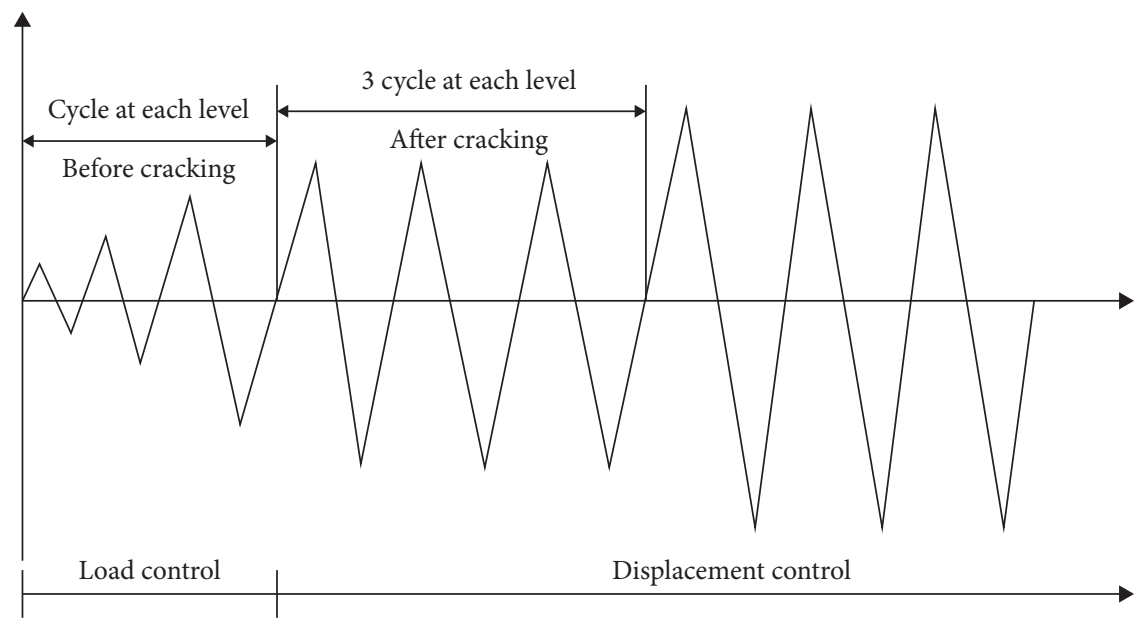

FIGURE 5: Loading system.

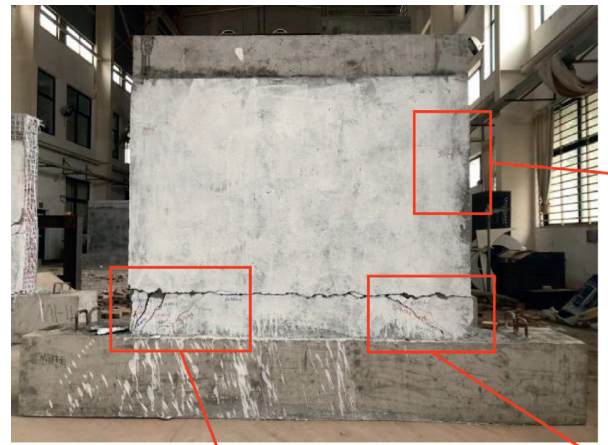

(a)

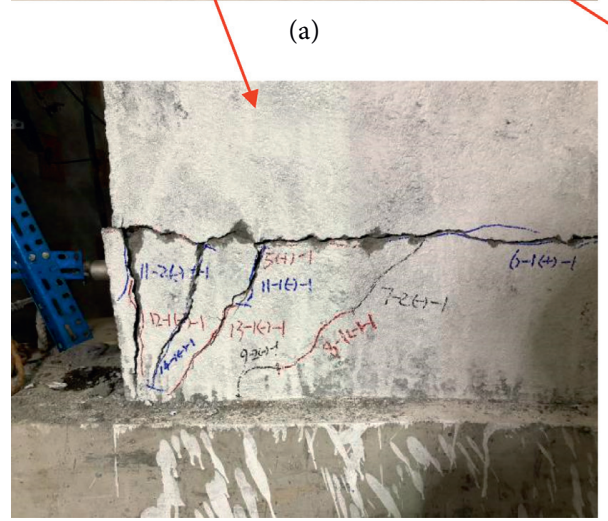

(c)

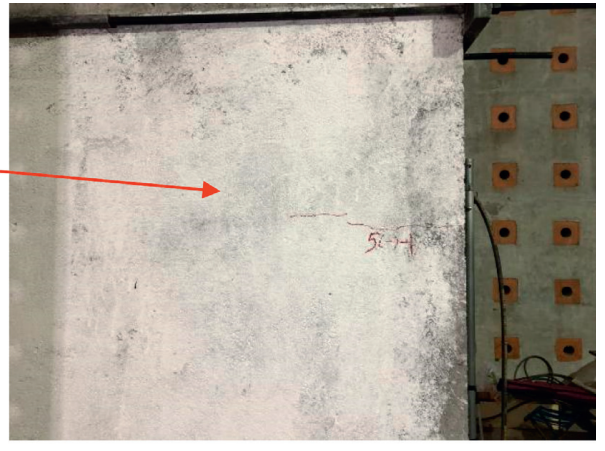

(b)

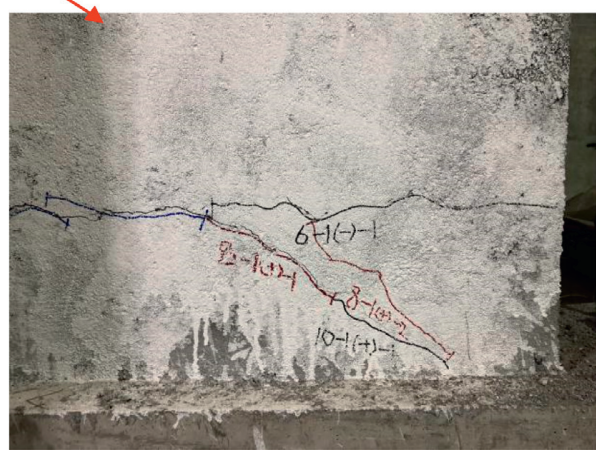

(d)

FiguRe 6: Damage mode of unstrengthened specimen W-1. (a) Overall damage, (b) local cracks, (c) damage in the bottom left corner, and (d) damage in the bottom right corner.

length of about $60 \mathrm{~cm}$ and a width of about $0.5 \mathrm{~mm}$ appeared between the 7 th and 8 th brick layers at the bottom of the wall. When loaded to $1.4 \mathrm{~mm}$, a diagonal crack developed along the middle of the wall and started to extend toward the lower right corner. When the displacement loaded to $2.1 \mathrm{~mm}$, the horizontal crack on the right side was connected, and the crack developed toward the bottom of the wall. When the displacement loaded to $3.5 \mathrm{~mm}$, the crack developed toward the bottom of the wall. At this moment, the through-slit was formed at the bottom of the wall. As the displacement increased, the plastering mortar began to fall off and the deformation of the PP-band could be clearly seen. Although the crack width increased, the wall can still withstand a large load, and the ductility of the wall had a great improvement. It can be seen that the PP-band played a great role in the loading process of the specimen, and the integrity of the PP-band reinforced specimen was very desirable. At the later stage of loading, the wall was detached from the bottom beam. The tearing sound of PPband could be heard at this moment, but the wall still had good integrity and bearing capacity. The damage is shown in Figure 8. 


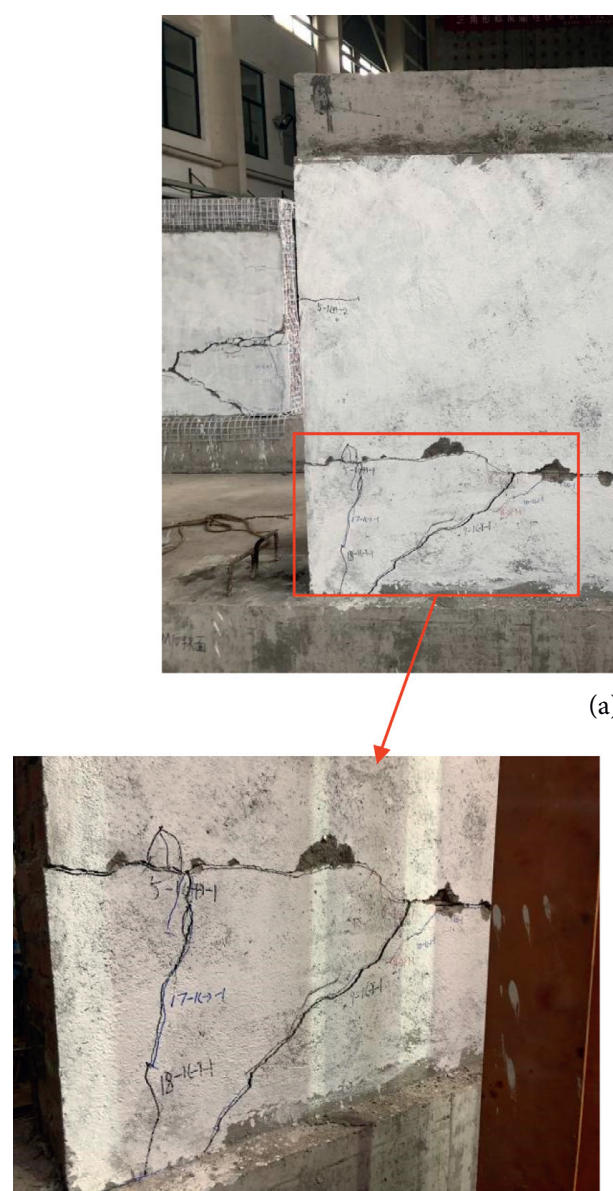

(b) (a)

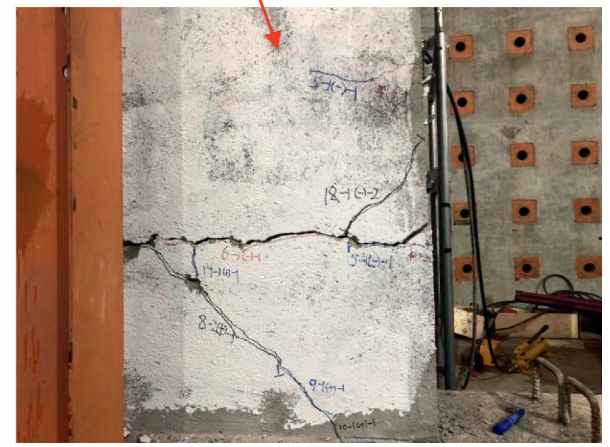

(c)

Figure 7: Damage mode of unstrengthened specimen W-2. (a) Overall damage, (b) damage in the bottom left corner, and (c) damage in the bottom right corner.

3.2.2. General Observation for Specimen JW-2. No cracks appeared in the wall before loading to $130 \mathrm{kN}$. When the forward force loaded to $130 \mathrm{kN}$, a crack with a width of about $2 \mathrm{~mm}$ was formed at the bottom left side of the wall. When loaded to $130 \mathrm{kN}$, the bottom of the right side of the wall was cracked, and a through-slit formed at the bottom of the wall. Then the displacement control was adopted. With the increase of the displacement, there was no new crack on the surface of the wall, the horizontal crack at the bottom was widened, and the corner was partially crushed. The horizontal load continued to rise at this moment. At the later stage of loading, the wall was sliding on the bottom beam. The loadcarrying capacity gradually decreased; finally, the shear-slip damage occurred. The damage is shown in Figure 9.

3.3. Analysis of Specimen Bearing Capacity. The cracking load and ultimate load values of each specimen are shown in Table 3. Cracking load refers to the load corresponding to the first crack in the wall, while ultimate load refers to the maximum load borne by the wall.

As can be seen from Table 3, compared with the unreinforced specimen $\mathrm{W}-1$, the unreinforced specimen $\mathrm{W}-2$ has a close cracking load. However, the ultimate bearing capacity of $\mathrm{W}-2$ has been greatly improved. The amplification is $26 \%$. Compared with the unreinforced specimen $\mathrm{W}-1$, the cracking load of the specimens JW-1 and JW-2 was increased by more than 20\%. This shows that the PP-band reinforcement has a certain inhibition effect on the cracking of the wall. The higher the strength of the plaster mortar, the better the inhibition effect. The ultimate load of the specimens reinforced by the PP-band increased by nearly $40 \%$. This shows that the stiffness of the wall has some improvement with the joint reinforcement of PP-band and plastering mortar. Also, the integrity and ultimate bearing capability of the jointed reinforced specimen are greatly enhanced as well.

3.4. Hysteresis Curve. Figure 10 shows the hysteresis curves of the four walls in the test. As shown in the figure, before the wall cracks, the hysteresis curve is linear and the hysteresis loop area is small. The wall is in the elastic working state. After the wall cracks, the wall is in the elastoplastic state with the increase of displacement. When the wall reaches the ultimate load, the bearing capacity of the wall decreases rapidly.

(1) Before reaching the ultimate load, the hysteretic loops of the unreinforced specimens $\mathrm{W}-1$ and $\mathrm{W}-2$ 


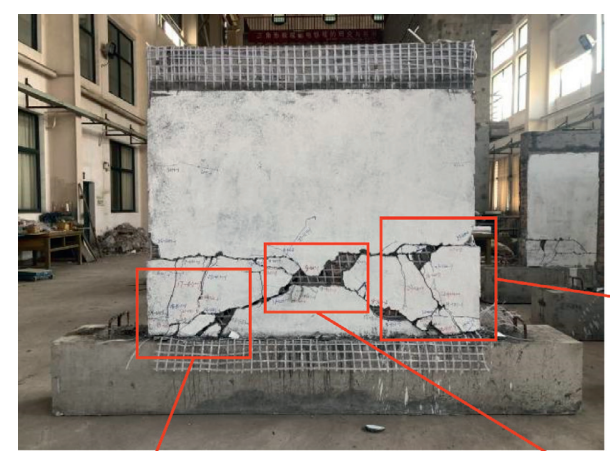

(a)

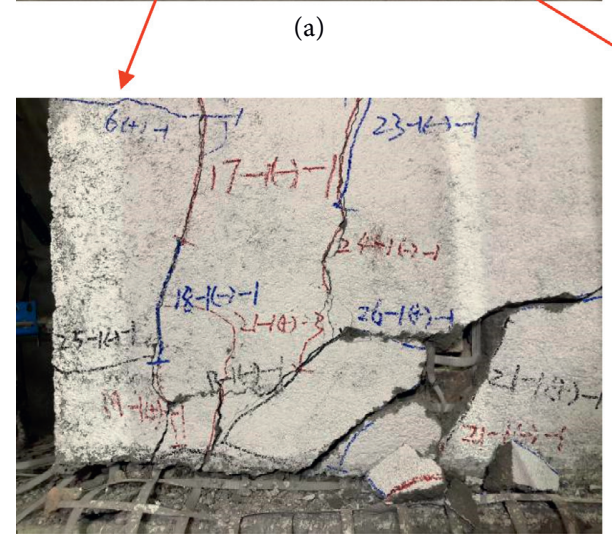

(c)

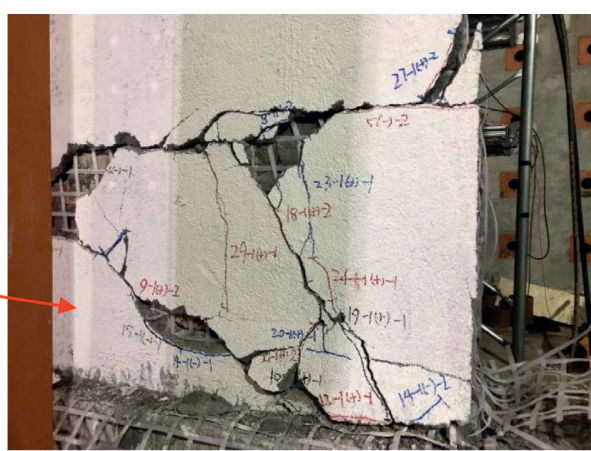

(b)

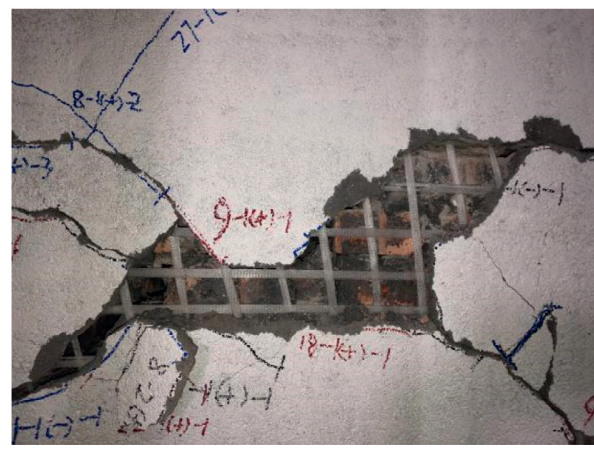

(d)

Figure 8: Damage mode of unstrengthened specimen JW-1. (a) Overall damage, (b) damage in the bottom left corner, (c) damage in the bottom right corner, and (d) The PP-band mesh is still working.

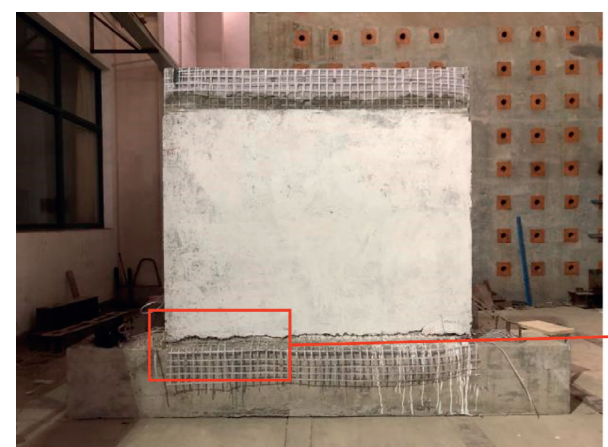

(a)

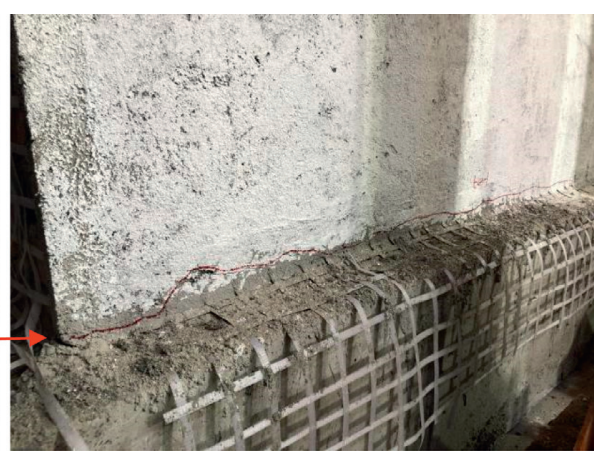

(b)

Figure 9: Damage mode of unstrengthened specimen JW-2. (a) Overall damage and (b) local cracks.

TABLE 3: Cracking load and ultimate load values of specimens.

\begin{tabular}{lcccc}
\hline $\begin{array}{l}\text { Specimen } \\
\text { number }\end{array}$ & $\begin{array}{c}\text { Cracking } \\
\text { load }(\mathrm{kN})\end{array}$ & $\begin{array}{c}\text { Amplification } \\
(\%)\end{array}$ & $\begin{array}{c}\text { Ultimate } \\
\text { load }(\mathrm{kN})\end{array}$ & $\begin{array}{c}\text { Amplification } \\
(\%)\end{array}$ \\
\hline W-1 & 104.3 & - & 180.7 & - \\
W-2 & 107.6 & 3.2 & 227.6 & 26.0 \\
JW-1 & 126.6 & 21.4 & 249.9 & 38.3 \\
JW-2 & 131.8 & 26.4 & 268.9 & 48.9 \\
\hline
\end{tabular}

are symmetrically distributed, and the hysteretic curves are in a $Z$ shape. After the ultimate load is reached, the area of hysteretic loop increases and the energy dissipation capacity increases as well. However, the hysteretic loop at both ends is asymmetric.
The area of the hysteretic loop at one end is full and the other end is small. The reason for this phenomenon is that the main cracks of the two specimens are appearing at the bottom $1 / 3$ of the wall, forming the horizontal penetrating cracks. Under the large deformation, the wall slid on the bottom beam, resulting in the small hysteresis loop area. The plastering mortar strength of unreinforced specimen $\mathrm{W}-2$ is higher than that of $\mathrm{W}-1$; the ultimate bearing capacity of $\mathrm{W}-2$ is also higher.

(2) Before cracking, the hysteretic curve area of PP-band reinforced specimens JW-1 and JW-2 is small. However, compared with the unreinforced specimens, the cracking load of reinforced specimens has 


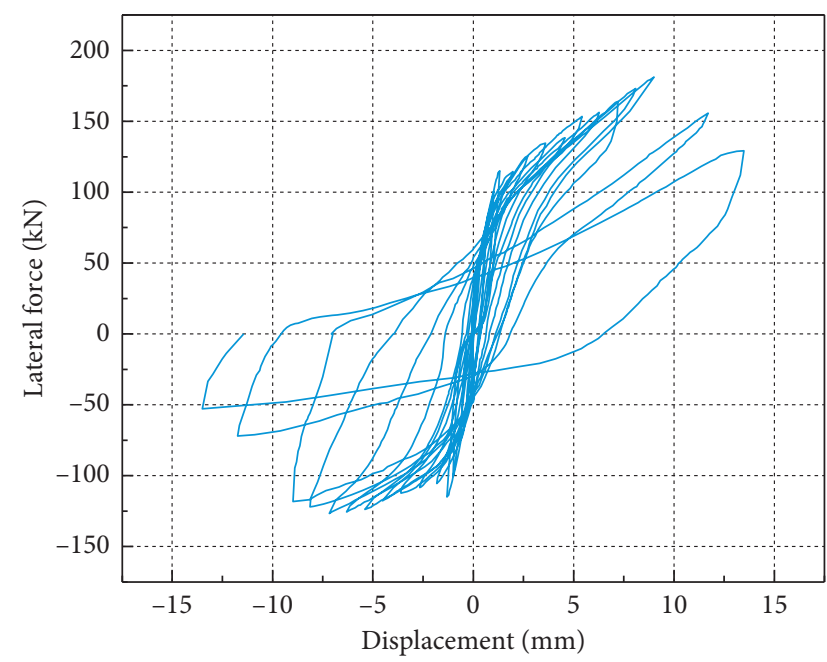

(a)

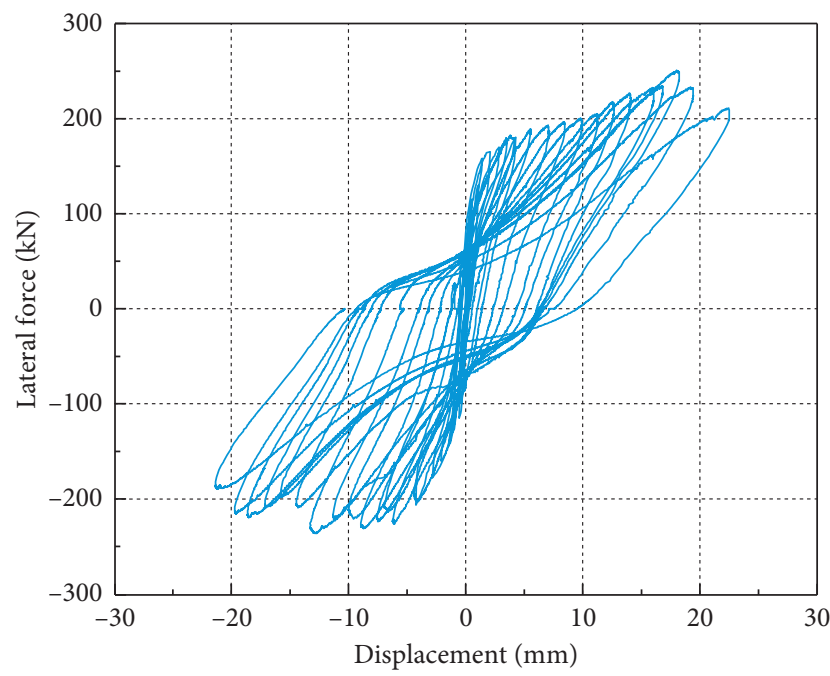

(c)

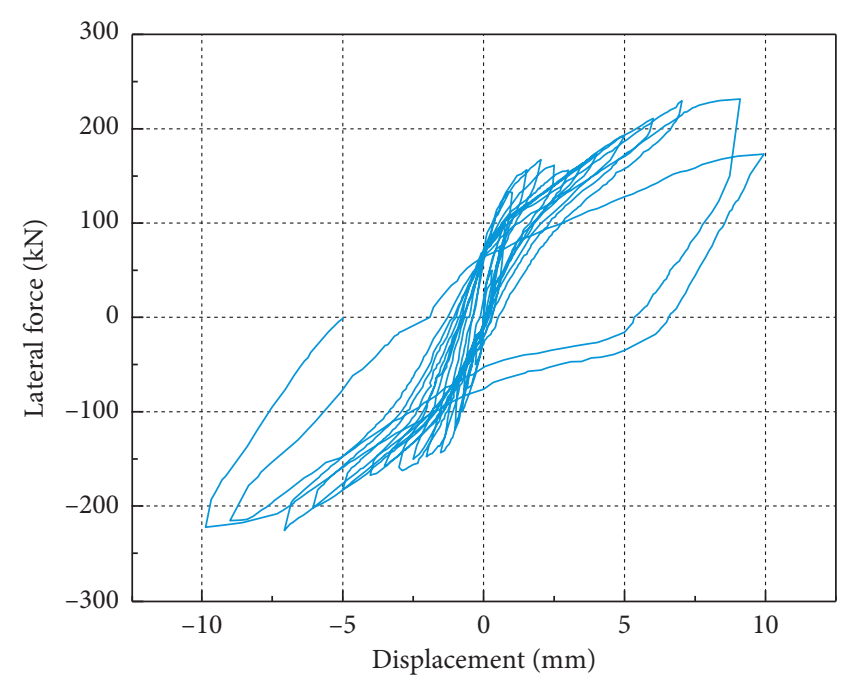

(b)

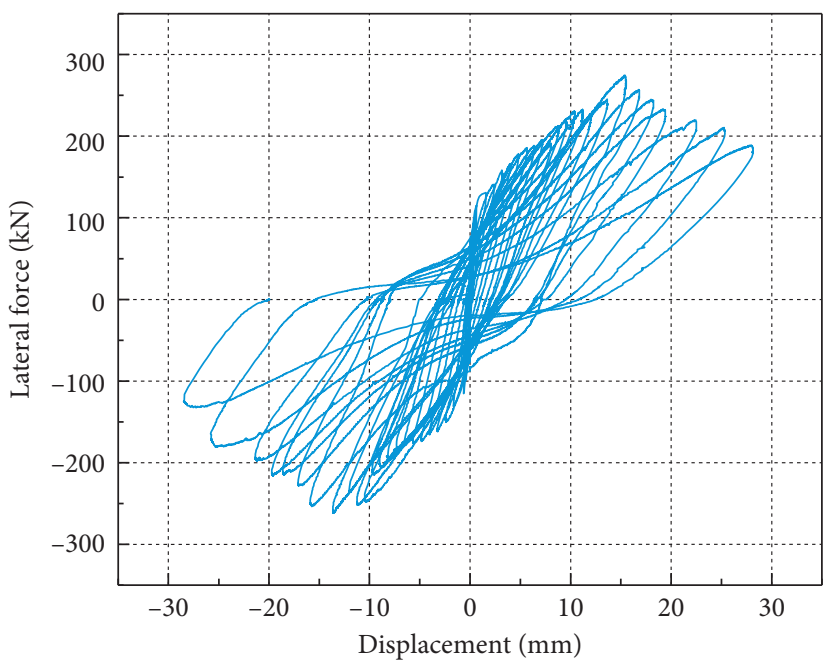

(d)

FIgURE 10: Hysteretic curve of specimens. (a) Specimen W-1, (b) specimen W-2, (c) specimen JW-1, and (d) specimen JW-2.

been increased. It shows that the contribution of PPband is small at this moment. After cracking, the hysteretic curve changed from $\mathrm{z}$ shape to s shape, and the area of the hysteretic loop increases at each level. This shows that the PP-band begins to play a significant role and the energy dissipation capacity is improved. The ultimate bearing capacity of JW-2 is greater than that of JW-1. High strength plastering mortar can improve the integrity of the PP-band and the wall. The hysteresis loop area of JW-2 is larger than that of JW-1, and the energy consumption capacity of JW-2 is better.

(3) The ultimate bearing capacity of specimens JW-1 and JW-2 is greatly improved compared with that of the $\mathrm{W}-1$ and $\mathrm{W}-2$. Particularly, when the ultimate load is reached, the specimens without PP-band reinforcement soon lose their bearing capacity. Then the walls slide on the bottom beam until they reach the failure state, causing obvious brittle failure. Due to the joint action of the PP-band and the plastering mortar, the integrity of the specimens JW-1 and JW2 is enhanced. After the ultimate load is reached, the specimens do not quickly lose the bearing capacity. Due to the restraint of the PP-band, the area of the hysteresis loop of JW-1and JW-2 is fuller and the hysteresis loop is symmetrically distributed.

(4) The displacement of specimens reinforced by PPband is significantly increased when they reached the ultimate load. Particularly the displacement of specimen JW-1 is larger than that of $\mathrm{W}-1$ and $\mathrm{W}-2$. At specimen with PP-band reinforcement, the maximum displacement is also nearly doubled. This shows that the joint reinforcement of the plastering mortar and PP-band not only increased the ultimate load of the specimen but also enhanced the ultimate displacement. In other words, the specimens 
reinforced by PP-band can bear large load under large deformation.

3.5. Skeleton Curve. Figure 11 shows the skeleton curve of the four walls in this experiment. The skeleton curve refers to the envelope curve of the hysteretic curve. It can be seen from the figure that the mechanical properties of the four specimens are in different loading status. The skeleton curve is almost straight before cracking, and the wall is in the elastic stage. After the wall cracks, the skeleton curve begins to bend, showing that the loading state of the wall is in a nonlinear state. When the wall reaches the ultimate load, the bearing capacity decreases and the wall is in the state of failure.

(1) After reaching the ultimate load, the skeleton curve of specimens W-1 and W-2 drops faster. Due to the higher strength of the plastering mortar of the specimen $\mathrm{W}-2$, its ultimate load is greater than $\mathrm{W}-1$. Although the plastering mortar reinforcement can increase the ultimate load of the wall, it does not constrain the cracking process of the wall.

(2) After reaching the ultimate load, the skeleton curve of specimens JW-1 and JW-2 declines slowly. It shows that the reinforcement of $\mathrm{PP}$-Band can restrain the extension of crack and damage to the wall. The strength of the plastering mortar has a certain influence on the reinforcement effect of the PP-Band. Specimen JW-2 with high strength plastering mortar, ultimate load, and ultimate displacement are greater than the specimen JW-1. It indicates that PP-band reinforcement with higher strength plastering mortar can better improve the integrity between the wall and PP-band.

(3) The ultimate load of the PP-band reinforced specimens JW-1 and JW-2 is larger than the unreinforced specimens $\mathrm{W}-1$ and $\mathrm{W}-2$. In the forward loading, when the PP-band reinforced specimen reaches the peak load, the corresponding displacement is larger than of that unreinforced specimen. It shows that the specimens reinforced by PP-band have the better bearing capacity and deformability.

3.6. Stiffness Degradation Curve. Stiffness degradation refers to the phenomenon that the displacement of a structure increases with the increase of applied times of the same load. This indicator reflects the process of specimens' damage accumulation.

In Figure 12, the secant stiffness is used to express the degradation of the specimens' stiffness. The abscissa represents the horizontal displacement, and the ordinate represents the ratio of the secant stiffness of each stage [26]:

$$
K_{i}=\frac{\left|+P_{i}\right|+\left|-P_{i}\right|}{\left|+X_{i}\right|+\left|-X_{i}\right|},
$$

where $+P_{i}$ and $-P_{i}$ are the peak load in the forward and backward loading process and $+X_{i},-X_{i}$ are the peak displacement in the forward and backward loading process.

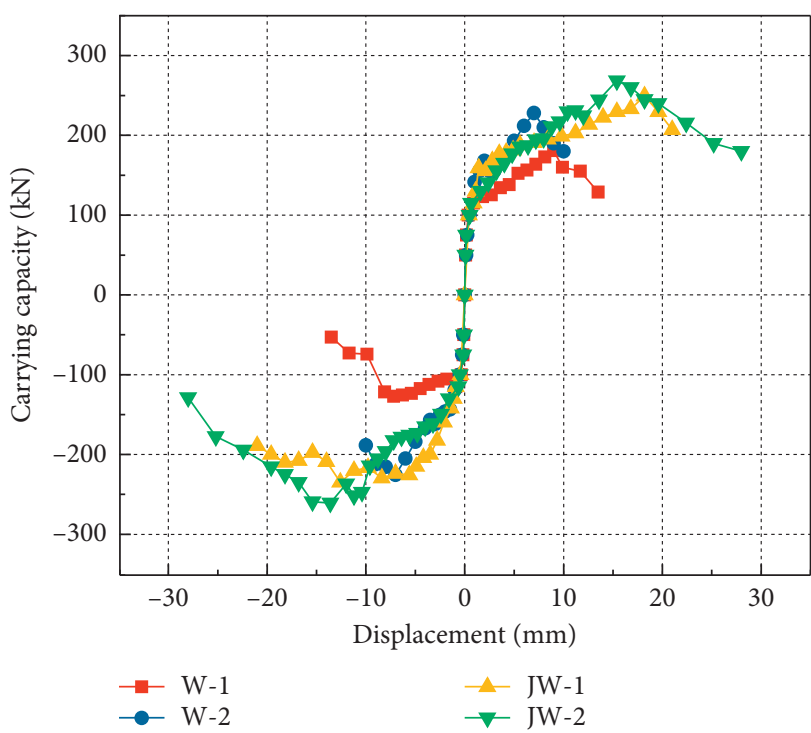

FIGURE 11: Skeleton curves of specimens.

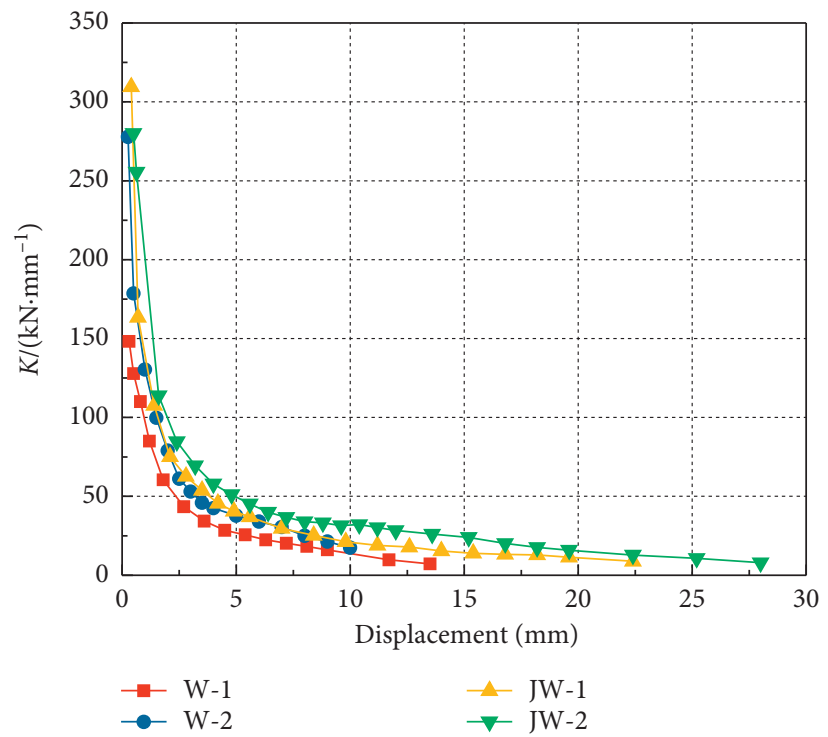

Figure 12: Stiffness degradation curve.

Figure 12 is the stiffness degradation curve obtained by the above formula.

(1) In the elastic stage, the longer the curve the greater the stiffness. It can be known by comparison that, in the elastic stage, the curve length of specimens JW-1 and JW-2 is longer than that of specimens W-1 and $\mathrm{W}$-2. This shows that PP-band can improve the stiffness of the wall.

(2) The higher the stiffness degradation curve the slower the stiffness degradation. By comparison, it can be seen that the stiffness degradation curve of specimen $\mathrm{W}-1$ is lower than that of JW-2. The stiffness degradation of JW-1 lags behind the $\mathrm{W}-2$. This shows that the strength of plastering mortar and PP-band has a certain influence on the stiffness degradation. The higher the strength of plastering mortar, the 


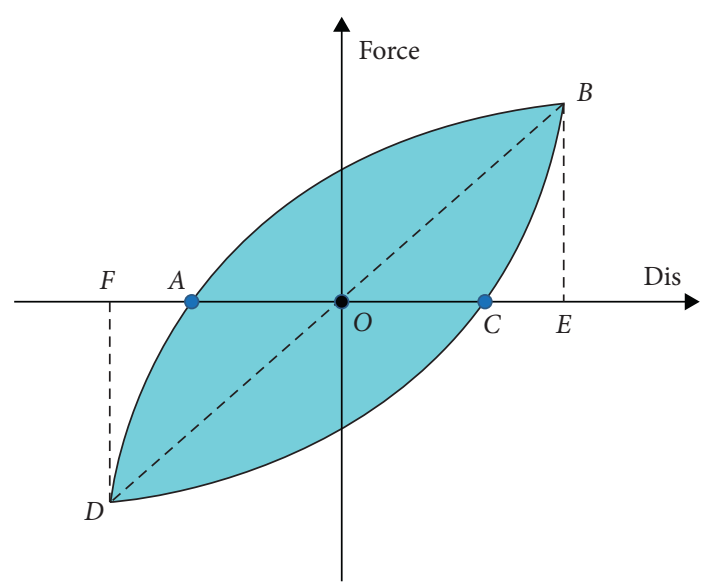

Figure 13: Calculation of energy dissipation coefficient.

TABLE 4: Characteristic parameters of specimens.

\begin{tabular}{lccccc}
\hline $\begin{array}{l}\text { Specimen } \\
\text { number }\end{array}$ & $\begin{array}{c}\text { Ductility } \\
\text { coefficient } \mu\end{array}$ & Amplification (\%) & $\begin{array}{c}\text { Energy dissipation } \\
\text { coefficient } E\end{array}$ & $\begin{array}{c}\text { Amplification } \\
(\%)\end{array}$ & $\begin{array}{c}\text { Equivalent damping coefficient } \\
\zeta_{e p}\end{array}$ \\
\hline W-1 & 13.50 & - & 1.56 & - & 0.25 \\
W-2 & 18.27 & 35.3 & 1.65 & 5.7 & 0.26 \\
JW-1 & 32.14 & 138 & 1.91 & 22.4 & 0.30 \\
JW-2 & 44.06 & 226 & 2.3 & 47.4 & 0.37 \\
\hline
\end{tabular}

slower the stiffness degradation. The reinforcement of the PP-band has a greater impact on stiffness degradation. The joint reinforcement of the PP-band and plastering mortar has a better restraint effect on the masonry wall, which enhances the integrity of the wall.

3.7. Deformation Capacity and Energy Dissipation Capacity. The ductility reflects the plastic deformation capacity of the structure. The greater ductility means that the structure can dissipate more seismic energy and withstand stronger inelastic deformation.

Ductility of the structure is generally reflected by the ductility coefficient $\mu$ [26]:

$$
\mu=\frac{\Delta_{u}}{\Delta_{\mathrm{cr}}}
$$

where $\Delta_{u}$ is ultimate displacement representing the displacement value corresponding to the $85 \%$ ultimate load and $\Delta_{\text {cr }}$ is wall cracking displacement corresponding to cracking load.

Energy dissipation capacity is an important indicator to measure the seismic performance of a structure. The energy dissipation capacity of the structure is usually determined by the energy dissipation coefficient $E$ or the equivalent viscous damping coefficient $\zeta_{\text {ep }}$, which is calculated by the area enclosed by the displacements load curve (Figure 13). The energy dissipation coefficient $E$ and the equivalent viscous damping coefficient $\zeta_{\text {ep }}$ are calculated as follows [26]:

$$
\begin{aligned}
E & =\frac{S(\mathrm{ABC}+\mathrm{CDA})}{S(\mathrm{OBE}+\mathrm{ODF})}, \\
\zeta_{\mathrm{ep}} & =\frac{1}{2 \pi} \cdot \frac{S(\mathrm{ABC}+\mathrm{CDA})}{S(\mathrm{OBE}+\mathrm{ODF})},
\end{aligned}
$$

where $S(\mathrm{ABC}+\mathrm{CDA})$ is area enclosed by a hysteresis curve; $S(\mathrm{OBE}+\mathrm{ODF})$ is sum of area of triangle OBE and ODF.

Table 4 shows the test characteristic parameters of each specimen. It can be seen from the table that the plastering mortar and PP-band have certain effects on the ductility and energy dissipation capacity of the wall. W-1 was plastered by lower strength plastering mortar. Ductility and energy dissipation coefficient of $\mathrm{W}-1$ are smaller. $\mathrm{W}-2$ was plastered by higher strength plastering mortar. The ductility of $\mathrm{W}-2$ has increased by $35.3 \%$, but the increase of energy dissipation coefficient is not obvious. It shows that, in view of the unreinforced specimens, the strength of plastering mortar is helpful to improve the ductility of wall. However, the effect on improving the energy dissipation capacity of the specimen is not obvious. Compared to the specimen $\mathrm{W}-1$, the ductility coefficient of JW-1 and JW-2 has increased by $138 \%$ and $226 \%$; also, the energy dissipation capacity has increased by $22.4 \%$ and $47.4 \%$. It shows that the ductility and energy dissipation of the wall reinforced by PP-band are significantly enhanced. Compared to the specimen JW-1, ductility and energy dissipation coefficient of specimen JW-2 have increased by $43 \%$ and $20.4 \%$. It shows that the strength of the plastering mortar has great effect on PP-band reinforcing system. In the joint reinforcement system, the higher strength plastering mortar helps to improve the enhancement effect of ductility and energy dissipation capacity.

\section{Conclusion}

The serious loss caused by earthquake disaster to human society is obvious to all. How to reduce the impact of earthquake disaster is one of the focal issues in the field of earthquake resistance. The reinforcement of PP-band 
provides a new way to solve this problem. As an industrial product widely used in the field of logistics and transportation, PP-band has many outstanding advantages such as good tensile performance, low density, and strong durability. The desirable mechanical properties of PP-band are of great significance for improving the brittle failure characteristics of masonry structures. PP-band mesh is wrapped on the outer surface of the wall in the form of a mesh, which can effectively restrain the cracked wall and improve its integrity and resistance to continuous collapse. Also, compared with other reinforcement methods, the low cost and convenient construction of this method can guarantee the low cost of reinforcement project. This reinforcement method has good applicability for the economically backward areas.

In this paper, the low-frequency cyclic loading tests are carried out on four masonry walls with or without PP-band reinforcement. The effects of different plastering mortar strengths and PP-bands on the seismic performance of masonry walls are considered. The conclusions have reference values for the popularization and application of PPband reinforcement technology in rural areas. The conclusions are as follows.

(1) For masonry walls without PP-band reinforcement, the plastering mortar with higher strength has improved the ultimate bearing capacity and ductility of the masonry walls by $26 \%$ and $35.3 \%$. However, the energy dissipation capacity enhancement effect of plastering mortar is not significant. For masonry walls reinforced by PP-band, the ductility and energy dissipation have been improved to a certain extent, with increases of $37.1 \%$ and $20.4 \%$.

(2) For unreinforced masonry walls, the plastering mortar contributes more to the ultimate loadbearing capacity and ductility. For the PP-band reinforced masonry walls, the increase in ultimate bearing capacity depends mainly on PP-band while the plastering mortar contributes more to the ductility and energy consumption.

(3) The increase in cracking load, ultimate carrying capacity, ductility, and energy dissipation of the masonry walls reinforced by PP-band is up to $26.4 \%$, $48.9 \%, 226 \%$, and $47.4 \%$. It indicates that the joint work of plastering mortar and PP-band has greatly improved the seismic performance indicators of masonry walls.

(4) PP-band can increase the rigidity of the masonry wall, enhance the integrity of the wall, and suppress cracking of the wall. Particularly under large deformation, it can still ensure that the masonry wall has a large bearing capacity. Thus, PP-band reinforcement has great significance in avoiding the collapse of the overall structure.

(5) PP-band reinforcement can constrain the masonry wall, improve the fullness of the hysteresis curve, and effectively increase the energy dissipation capacity of the masonry wall. The PP-band has a great contribution to the ductility of the masonry structure. The ductility of the PP-band reinforced masonry wall is increased by more than 2 times.

(6) May be due to the greatly improved integrity, the through-slit formed at the bottom of PP-bandreinforced JW-2. To avoid the similar phenomenon, the connection between the PP-band and the foundation could be strengthened.

\section{Data Availability}

The data used to support the findings of this study are available from the corresponding author upon request.

\section{Conflicts of Interest}

The authors declare that they have no conflicts of interest.

\section{Acknowledgments}

This work was financially supported by the National Natural Science Foundation of China (51608249 and 51968047) and Key Research and Development Program of Jiangxi Province (20161BBG70058).

\section{References}

[1] S. Bhattacharya, S. Nayak, and S. C. Dutta, "A critical review of retrofitting methods for unreinforced masonry structures," International Journal of Disaster Risk Reduction, vol. 7, pp. 51-67, 2014.

[2] I. Papagianni and V. Pachta, "Constructional characteristics and restoration aspects of historic earth block structures," Research on Engineering Structures and Materials, vol. 11, pp. 39-51, 2017.

[3] R. Jasiński, "Research on the influence of bed joint reinforcement on strength and deformability of masonry shear walls," Materials, vol. 12, no. 16, p. 2543, 2019.

[4] N. Gattesco, C. Amadio, and C. Bedon, "Experimental and numerical study on the shear behavior of stone masonry walls strengthened with GFRP reinforced mortar coating and steelcord reinforced repointing," Engineering Structures, vol. 90, pp. 143-157, 2015.

[5] R. El-Hacha, R. Wight, and M. Green, "Prestressed fibrereinforced polymer laminates for strengthening structures," Progress in Structural Engineering and Materials, vol. 3, no. 2, pp. 111-121, 2001.

[6] A. A. Allawi, "Behavior of strengthened composite prestressed concrete girders under static and repeated loading," Advances in Civil Engineering, vol. 2017, Article ID 3619545, 13 pages, 2017.

[7] R. Hassanli, M. A. ElGawady, and J. E. Mills, "Experimental investigation of in-plane cyclic response of unbonded posttensioned masonry walls," Journal of Structural Engineering, vol. 142, no. 5, Article ID 04015171, 2016.

[8] Z. Al-Jaberi, J. J. Myers, and M. A. ElGawady, "Experimental and analytical approach for prediction of out-of-plane capacity of reinforced masonry walls strengthened with externally bonded FRP laminate," Journal of Composites for Construction, vol. 23, no. 4, Article ID 04019026, 2019.

[9] Z. Al-Jaberi, J. J. Myers, and M. A. ElGawady, "Out-of-plane flexural behavior of reinforced masonry walls strengthened 
with near-surface-mounted fiber-reinforced polymer," $A C I$ Structural Journal, vol. 115, no. 4, 2018.

[10] Z. Draidi, T. T. Bui, A. Limam, H. V. Tran, and A. Bennani, "Buckling behavior of metallic cylindrical shell structures strengthened with CFRP composite," Advances in Civil Engineering, vol. 2018, Article ID 4231631, 13 pages, 2018.

[11] Z. A. Al-Jaberi, J. J. Myers, and M. A. ElGawady, "Evaluation of FRP and FRCM composites for the strengthening of reinforced masonry walls," Journal of the American Concrete Institute, vol. 327, pp. 32.1-32.6, 2018.

[12] Z. Al-Jaberi, J. J. Myers, and M. A. ElGawady, "Pseudo-static cyclic loading comparison of reinforced masonry walls strengthened with FRCM or NSM FRP," Construction and Building Materials, vol. 167, pp. 482-495, 2018.

[13] S. Babaeidarabad, D. Arboleda, G. Loreto, and A. Nanni, "Shear strengthening of un-reinforced concrete masonry walls with fabric-reinforced-cementitious-matrix," Construction and Building Materials, vol. 65, pp. 243-253, 2014.

[14] P. Mayorca and K. Meguro, "Efficiency of polypropylene bands for the strengthening of masonry structures in developing countries," in Proceedings of the 5th International Summer Symposium, Japan Society of Civil Engineers (JSCE), pp.125-128, Tokyo, Japan, 2003.

[15] P. Mayorca and K. Meguro, "Proposal of an Efficient Technique for Retrofitting Unreinforced Masonry Dwellings," in Proceedings of the 13th World Conference on Earthquake Engineering, pp. 1-6, Vancouver, BC, Canada, 2004.

[16] N. Sathiparan, P. Mayorca, K. N. Neshali, R. Guragain, and K. Meguro, "Experimental study on unburned brick masonry wallettes retrofitted by PP-band meshes," Seisan Kenkyu, vol. 58, no. 3, pp. 301-304, 2006.

[17] J. Macabuag, J. S. Bhattacharya, and T. Blakeborough, "Extending the collapse time of non-engineered masonry buildings under seismic loading," in Proceedings of the 14th World Conference on Earthquake Engineering, pp. 12-17, Beijing, China, 2008.

[18] N. Sathiparan, P. Mayorca, and K. Meguro, "Parametric study on diagonal shear behavior of masonry wall retrofitted by PPband mesh," in Proceedings of the 26th Annual Conference of Japan Society for Natural Disaster Science, CD-ROM, Sapporo, Japan, 2007.

[19] N. Sathiparan, P. Mayorca, and K. Meguro, "Shake table tests on one-quarter scale models of masonry houses retrofitted with PP-band mesh," Earthquake Spectra, vol. 28, no. 1, pp. 277-299, 2012.

[20] N. Sathiparan, K. Sakurai, M. Numada, and K. Meguro, "Experimental investigation on the seismic performance of PP-band strengthening stone masonry houses," Bulletin of Earthquake Engineering, vol. 11, no. 6, pp. 2177-2196, 2013.

[21] B. T. Sun, P. D. Huang, X. Q. Yao, and Q. Zhou, "Seismic test research of typical single story masonry retrofitted with PPband in Tibet," World Earthquake Engineering, vol. 34, no. 1, pp. 40-50, 2018.

[22] Q. Zhou, S. Chen, B. T. Sun, and Y. C. Yang, "Study on the shaking table test of single storey masonry structure with a seismic system of constructional column and ring beam," Journal of Harbin Engineering University, vol. 38, no. 10, pp. 1650-1660, 2017.

[23] M. U. Saleem, M. Numada, M. N. Amin, and K. Meguro, "Seismic response of PP-band and FRP retrofitted house models under shake table testing," Construction and Building Materials, vol. 111, pp. 298-316, 2016.

[24] N. Ning, Z. John Ma, P. Zhang, D. Yu, and J. Wang, "Influence of masonry infills on seismic response of RC frames under low frequency cyclic load," Engineering Structures, vol. 183, pp. 70-82, 2019.

[25] N. Sathiparan and K. Meguro, "Seismic behavior of low earthquake-resistant arch-shaped roof masonry houses retrofitted by PP-band meshes," Practice Periodical on Structural Design and Construction, vol. 17, no. 2, pp. 54-64, 2012.

[26] F. Wu, H. T. Wang, G. Li, J. Q. Jia, and H. N. Li, "Seismic performance of traditional adobe masonry walls subjected to in-plane cyclic loading," Materials and Structures, vol. 50, no. 1, p. $69,2017$. 